\title{
Intradialytic Hypertension: It Is Time to Act
}

Charles Chazot Guillaume Jean

NephroCare, Tassin, France

\section{Key Words}

Hemodialysis · Hypertension - Blood pressure •

Extracellular fluid · Renin • Endothelin - Catecholamine •

Cardiac output $\cdot$ Peripheral resistances

\begin{abstract}
Intradialytic hypertension (IDH) is defined by blood pressure (BP) values during and at the end of the dialysis session exceeding BP values at dialysis onset. It occurs in around 10\% of hemodialysis (HD) patients. It is associated with HD patients' hospitalization and increased risk of death. Many hypotheses have been proposed to explain this phenomenon. Recent studies and reports highlight the important role of fluid overload, hemodynamic changes, and increased endothelin level. The importance of other hypotheses such as the renin-angiotensin system activation, sympathetic overactivity and ionic variations seems secondary but it deserves to be confirmed. Fluid removal remains the key point for treating IDH. Several important unanswered questions remain and the need for further research is highlighted.
\end{abstract}

Copyright $\odot 2010$ S. Karger AG, Basel

Many nephrologists have been paged during calls by dialysis nurses because one of their patients was presenting with severe hypertension at the time of dialysis disconnection. This situation may appear trivial and has been only recently thoroughly studied. It has been called paradoxical hypertension [1] because it occurs during ultrafiltration (UF) $[2,3]$ and can be referred to as intradialytic hypertension (IDH). Many hypotheses have been proposed to explain this phenomenon (table 1). However, recent studies and reports allow this table to be simplified. This review focuses on the recent evidence regarding the pathophysiology of this phenomenon, proposes therapy based on this new knowledge and offers research hypotheses for the remaining unanswered questions.

\section{Definition and Prevalence of IDH}

As pointed out by Chou et al. [4], there is no uniform definition of IDH. In table 2, several proposed criteria for this diagnosis are summarized. In our opinion, it can be defined as a sustained increase of blood pressure (BP) during the dialysis session with $\mathrm{BP}$ values during and at the end of the dialysis session exceeding BP values at dialysis onset. We are not convinced that it is necessary to frame this definition with strict numbers. The repetition of the phenomenon over the sessions must alert the physician and trigger clinical decision.

The patient can be normotensive at the start of dialysis, but the BP rise during the hemodialysis (HD) session makes the patient hypertensive during and at the end of the session. It also may happen when the predialysis BP

\section{KARGER \\ Fax +4161306 1234 \\ E-Mail karger@karger.ch}

www.karger.com
(C) 2010 S. Karger AG, Basel

$1660-2110 / 10 / 1153-0182 \$ 26.00 / 0$

Accessible online at:

www.karger.com/nec
Dr. Charles Chazot

NephroCare

42, Avenue du 8 Mai 1945

FR-69160 Tassin (France)

Tel. +33 6622 33130, Fax +33 4783 48703, E-Mail chchazot@ gmail.com 
Table 1. Proposed mechanisms for IDH

1 Renin-angiotensin system activation because of UF-induced hypovolemia

2 Sympathetic overactivity

3 Intradialytic $\mathrm{K}^{+} / \mathrm{Ca}^{2+}$ variations

4 Blood viscosity/hemoconcentration-induced vasoconstriction, favored by EPO treatment

5 Fluid overload

6 Increased cardiac output

7 Endothelin-driven vasoconstriction

8 Antihypertensive drugs removal by dialysis treatment

$\mathrm{UF}=$ Ultrafiltration; $\mathrm{EPO}=$ erythropoietin

Table 2. Definitions of IDH from clinical studies and reviews

\begin{tabular}{ll}
\hline Reference & Definitions of IDH \\
\hline Amerling et al. [5] & $\begin{array}{l}\text { 15-mm Hg increase of mean arterial } \\
\text { pressure between the start and the end of the } \\
\text { dialysis session }\end{array}$ \\
\hline Cirit et al. [3] & $\begin{array}{l}\text { BP is higher at the end of the dialysis session } \\
\text { than at the dialysis onset in more than 50\% } \\
\text { of the dialysis sessions }\end{array}$ \\
\hline Gunal et al. [12] & $\begin{array}{l}\text { BP exceeds initial values during } 4 \text { dialysis } \\
\text { sessions in a row }\end{array}$ \\
\hline Chou et al. [4] & $\begin{array}{l}\text { Normal or high BP at initiation of dialysis, } \\
\text { followed by a mean arterial BP increase of } \\
15 \text { mm Hg during more than two-thirds of } \\
\text { the most recent 12 treatment sessions }\end{array}$ \\
\hline Chen et al. [2] & $\begin{array}{l}\text { Hypertension that appears resistant to UF } \\
\text { and which occurs during or immediately } \\
\text { after the dialysis procedure }\end{array}$ \\
\hline Inrig et al. [9] & \begin{tabular}{l}
$\geq 10$-mm Hg systolic BP rise with HD \\
\hline
\end{tabular}
\end{tabular}

is high and then becomes even higher during the usual hourly BP check and at the dialysis disconnection. This $\mathrm{BP}$ rise may be very severe with an impressive hypertension crisis. IDH often happens in patients starting the dialysis treatment (incident patients) but is also seen in patients treated for months or years with dialysis (prevalent patients). The frequency of IDH has been reported to be around $10 \%$ of the HD patients. Analyzing a cohort of HD patients for 2 weeks, Amerling et al. [5] found IDH in $8 \%$. In the experience of Dorhout Mees [6], the phenomenon happens in $5-15 \%$ of the patients. Very recently, it was found in $12.2 \%$ of a large cohort of patients [7].
The patient survival is influenced by IDH. Zager et al. [8] have reported an increased risk of death when postdialysis systolic and diastolic BP were over 180 and $90 \mathrm{~mm} \mathrm{Hg}$ $(\mathrm{RR}=1.96$ and 1.73), respectively. An increased risk of hospitalization and death has been found by Inrig et al. [9] in patients with a $10-\mathrm{mm} \mathrm{Hg} \mathrm{BP}$ rise during the dialysis session.

By extension, it may also apply to patients with heart failure, with the usual low BP in this setting, with BP increasing during the session. Usually, these patients will not reach hypertension levels but the $\mathrm{BP}$ rise significance may be the same as in patients with intact cardiac function. This has been very recently confirmed by Inrig et al. [7] who found an increased risk of death only in patients with an intradialytic $10-\mathrm{mm} \mathrm{Hg}$ BP rise and a predialysis systolic BP $\leq 120 \mathrm{~mm} \mathrm{Hg}$.

\section{Biochemical, Hormonal and Autonomic Nervous System Status Associated with IDH}

Among the hypotheses to explain IDH, the most popular are the stimulation of the renin-angiotensin system by UF-induced hypovolemia, the overactivation of the sympathetic system, and the ionic variations, mainly involving potassium and calcium. These different assumptions have been tested in the study by Chou et al. [4]. These authors have analyzed the biochemical and hormonal status in $30 \mathrm{HD}$ patients presenting with IDH (the IDH group) at the onset and at the end of the dialysis session compared with $30 \mathrm{HD}$ patients without IDH (the control group). Antihypertensive medications were stopped for at least 2 weeks. No significant differences were present between groups except for the MAP level, which was higher in the IDH group. The results are summarized in table 3. During the session, the plasma renin and norepinephrine increased in the control group but not in the IDH group. The power spectral analysis of the heart rate variability from intradialytic Holter electrocardiogram recording did not find changes in the autonomic nervous system functioning in the hypertensionprone patients. No significant differences between the 2 groups were found in the potassium and calcium variations. Whereas the drop in nitric oxide (NO) was comparable in the 2 groups, the IDH group experienced a significant increase in plasma endothelin, which did not change in the control group. It confirms the previous finding by Raj et al. [10] who reported an increased plasma endothelin level in IDH patients. 


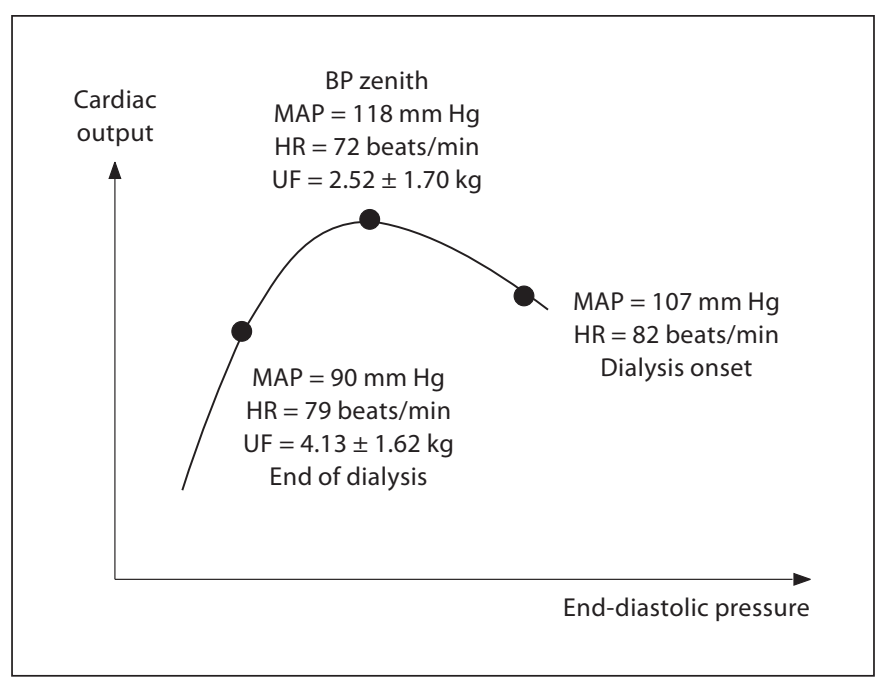

Fig. 1. Hemodynamic changes during the dialysis session in the study by Gunal et al. [12]. During the session the cardiac function improves with progressive moving from the right to the left side of the curve under the effect of prolonged UF, the BP being the highest at the zenith of the Starling curve. MAP = Mean arterial pressure; $\mathrm{HR}=$ heart rate.

Table 3. Summary of pre/post variations of biochemical/endocrine markers in IDH patients and in controls in the study by Chou et al. [4]

\begin{tabular}{llll}
\hline Pre/Post (plasma) & $\begin{array}{l}\text { IDH } \\
\text { group }\end{array}$ & $\begin{array}{l}\text { Control } \\
\text { group }\end{array}$ & $\begin{array}{l}\text { p value be- } \\
\text { tween groups }\end{array}$ \\
\hline Epinephrine & $\leftrightarrow$ & $\leftrightarrow$ & $\mathrm{NS}$ \\
Norepinephrine & $\leftrightarrow$ & $\uparrow$ & $<0.05$ \\
Renin & $\leftrightarrow$ & $\uparrow$ & $<0.05$ \\
Endothelin & $\uparrow$ & $\leftrightarrow$ & $<0.05$ \\
$\mathrm{~K}^{+}$ & $\downarrow$ & $\downarrow$ & $\mathrm{NS}$ \\
$\mathrm{Ca}^{2+}$ & $\uparrow$ & $\uparrow$ & $\mathrm{NS}$ \\
\hline
\end{tabular}

Going back to table 1, these findings by Chou et al. [4] deeply challenge the hypotheses 1,2 , and 3 . The absence of a plasma renin increase, whereas renin significantly rises in the control patients, contradicts the efficiency of captopril in preventing the $\mathrm{BP}$ rise during the dialysis session as reported by Bazzato et al. [11]. However, the captopril effect may be nonspecific due to its vasodilating properties, as Chou et al. [4] found an increase in peripheral vascular resistance in IDH patients. The absence of evidence of an increased sympathetic activity in this study remains to be confirmed by other methods explor- ing the sympathetic system. Furthermore, it is not very surprising that ionic variations were not found to be associated with IDH because they are often nonspecific and similar in the great majority of dialysis patients without IDH. The study by Chou et al. [4] thus strengthens the endothelin hypothesis (hypothesis 7 in table 1). However, this study is the only one which has extensively explored both biochemical and autonomic nervous function status in IDH patients. Complementary studies are needed to confirm its data.

\section{The Preeminent Lead of Sodium and Fluid Excess as the Cause of IDH (the Izmir Lesson)}

Our former and senior colleagues in Tassin, Guy Laurent and Bernard Charra, advised us empirically when facing IDH in one of our patients to decrease the dry weight. Two uncontrolled studies from Izmir, Turkey, have confirmed that this decision is appropriate. In the first study reported by Cirit et al. [3], 7 hypertensive patients presented with a BP increase from 172/99 $\mathrm{mm} \mathrm{Hg}$ at the start of the dialysis session to $204 / 114 \mathrm{~mm} \mathrm{Hg}$ at the end of the session. Only 3 of these patients had pedal edema. Tapering antihypertensive medications and decreasing the postdialysis body weight was applied in all the patients. In $9 \pm 3$ days and a body weight decrease of 6.7 $\mathrm{kg}$ (11\% of the body weight), the predialysis BP normalized to a mean of $126 / 78 \mathrm{~mm} \mathrm{Hg}$ with disappearance of the intradialytic increases of BP. The second study by Gunal et al. [12] reports echocardiography data in 6 patients with intradialytic BP increase. What is very original in this report is that as long as the systolic BP remained increased by $10 \mathrm{~mm} \mathrm{Hg}$ over the initial value, the time and $\mathrm{UF}$ rate are prolonged until the $\mathrm{BP}$ is normalized. Hence, the mean arterial pressure at the start of dialysis was 107 $\pm 5 \mathrm{~mm} \mathrm{Hg}$, reaching $118 \pm 6 \mathrm{~mm} \mathrm{Hg}$, with an average weight loss of $2.52 \pm 1.70 \mathrm{~kg}$ at the zenith of BP increase. After BP normalization using a prolonged session time and UF rate, the session time varied between 4 and $7 \mathrm{~h}$, the mean arterial pressure was $90 \pm 2 \mathrm{~mm} \mathrm{Hg}$ and the weight loss was $4.13 \pm 1.62 \mathrm{~kg}$. At the same time, the cardiac index and the ejection fraction increased significantly between the start of the session and the BP zenith and then decreased at the end of the session. This can be interpreted as the progressive and beneficial move of cardiac function along the Starling curve under the effect of UF (fig. 1). From these observations, even in the absence of control groups, it can be stated that IDH is associated with extracellular fluid excess and that a postdialysis- 
body weight decrease is able to correct the intradialytic $\mathrm{BP}$ rise. As in the report by Cirit et al. [3], Gunal et al. [12] mentioned in their study that only 1 patient presented with pedal edema. This point is very important. It underlines that fluid excess may be significantly present although the clinical examination does not show obvious fluid overload. These data confirm the hypotheses 5 and 6 in table 1, upholding fluid overload and hemodynamic changes as the main triggers for IDH during HD.

This conclusion is indirectly corroborated in the study by Chou et al. [4]. These authors display the hematocrit evolution in 2 groups (fig. 2). The progressive UF-induced rise of hematocrit because of the hemoconcentration is significantly lower in the IDH group. This may be interpreted as a greater refilling from the interstitial space in fluid-overloaded patients. It contradicts the mechanism proposed by Levin [1], in which an increased blood viscosity during the session would favor increased peripheral resistances and increased BP. It is stated in his report that IDH is more frequent since the erythropoietin era and higher predialysis hematocrit levels. However, it is difficult to confirm this statement from the literature. Hence, the hypothesis 4 in table 1 is not supported by the findings in the study by Chou et al. [4]. Nevertheless, it is necessary to be cautious before crossing out erythropoietin responsibility in IDH, because it is known that erythropoietin triggers endothelin synthesis [13].

A positive sodium balance is the main mechanism of extracellular fluid overload and hypertension in dialysis patients $[14,15]$. Sodium appears then as the culprit for IDH. In HD patients, the sodium balance becomes positive when dietary sodium intake exceeds sodium removal during dialysis and a low sodium diet should be advised in most dialysis patients [16]. The sodium balance may also become positive when the patient presents progressive fat and lean body mass loss without dry weight prescription adjustment. Although a high sodium concentration in dialysate has been used to improve dialysis tolerance, it increases sodium diffusion and exposes the patient to a high intradialytic sodium load [17-19]. The responsibility or mechanism of a positive dialysate-plasma sodium gradient in IDH is unknown [2]. Oberleithner et al. [20] demonstrated a dramatic and rapid stiffening effect of cultured endothelial cells in a high sodium concentration medium that was associated with NO synthesis down-regulation. A positive and large sodium gradient between the dialysate and the plasma as a hypothesis for IDH appears attractive and corroborates the findings by Chou et al. [4] on endothelium metabolism. However, these last authors provided the sodium dialysate concen-

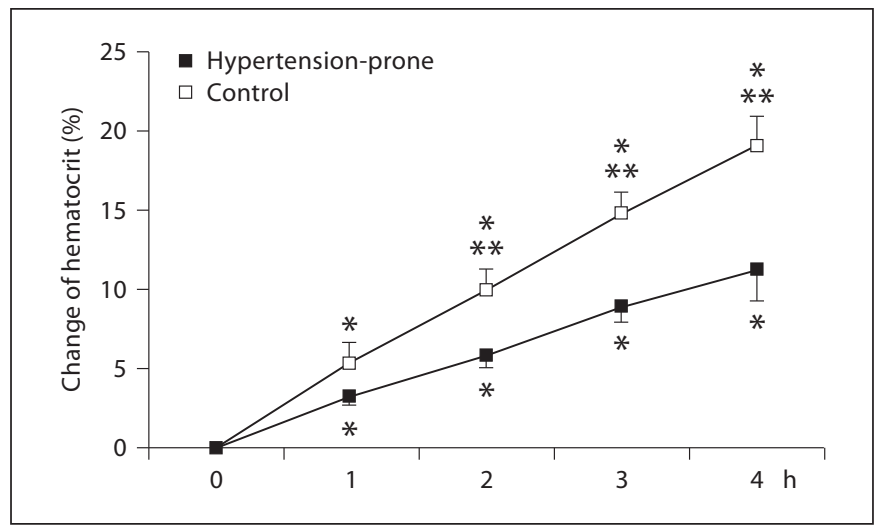

Fig. 2. Hematocrit evolution in both IDH and control patients in the study by Chou et al. [ 4 , with permission]. ${ }^{*} \mathrm{p}<0.05 \mathrm{vs}$. baseline values of the respective groups, ${ }^{* *} \mathrm{p}<0.05$ comparisons between the groups.

tration at $140 \mathrm{mmol} / \mathrm{l}$ but did not report the average plasma sodium or the potential dialysate-plasma sodium gradient in the hypertension-prone and control patients. Moreover, Oberleithner et al. [20] did not report the effects of sodium on the endothelin release; in the study by Chou et al. [4], the NO decrease during the dialysis treatment was not different between IDH-prone and control subjects. Song et al. [21] have studied patients' BP during a sodium positive-balance intradialytic sodium profiling. They did not find a significant BP increase during the dialysis session. However, the studied patients were hypotension-prone and therefore might not reflect the usual patients displaying IDH. van Kuijk et al. [22] did not find significant hemodynamic changes in 9 patients studied in a cross-over trial during combined HD and sustained UF with the sodium dialysate concentration at 134 and $144 \mathrm{mmol} / \mathrm{l}$. But in this report, the patients were studied only for $2 \mathrm{~h}$, a shorter period than the conventional HD treatment during which IDH occurs. Hence, no direct relationship between a potential intradialytic sodium load and IDH is established.

Is there a link between the sodium/fluid overload and the endothelin hypothesis reported by both Raj et al. [10] and Chou et al. [4]? Similar to the Oberleithner et al. [20] findings in vitro, Osanai et al. [23] showed in vivo that a large salt intake in dialysis patients modified the endothelium metabolism with a decreased $\mathrm{NO}$ and an increased asymmetrical dimethylarginine (ADMA) production. In the same way, shear stress forces applied on the endothelium had the same effect on NO and ADMA synthesis [24]. Unfortunately, endothelin was not studied 


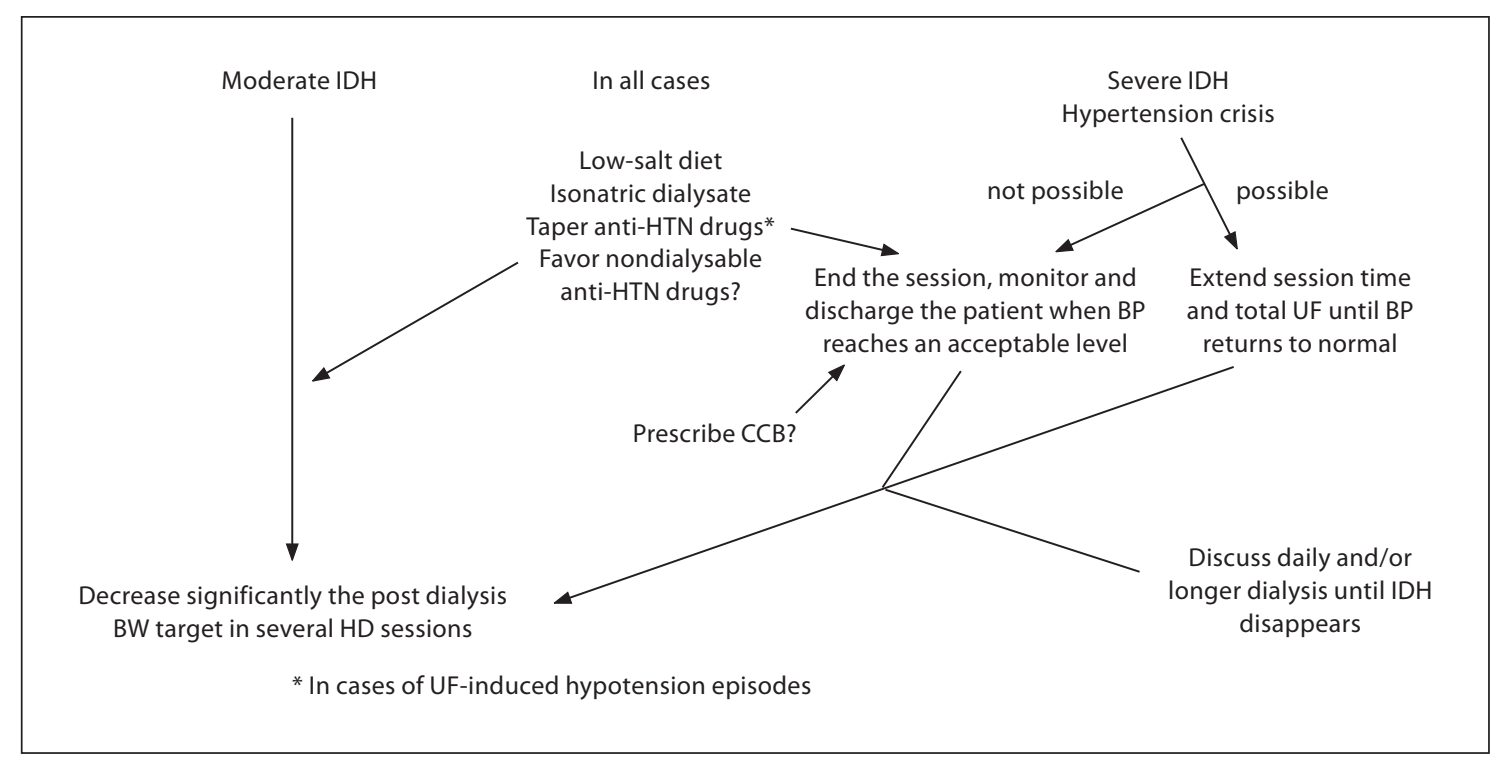

Fig. 3. Proposed algorithm to handle IDH according to its severity. Prescribing CCB in the case of severe IDH or favoring nondialyzable antihypertensive drugs appear to be opinion-based hypotheses and their effect on IDH has not been reported even in observational studies. $\mathrm{BW}=$ Body weight; $\mathrm{CCB}=$ calcium channel blockers; anti-HTN = antihypertensive.

in these reports. It can be hypothesized that in patients with significant fluid overload, the large refilling from interstitial space, as demonstrated in figure 1, may trigger endothelin synthesis and an increase in peripheral resistance. This phenomenon in combination with the improvement in cardiac function as reported by Gunal et al. [12] can explain the IDH phenomenon. It is true that in this last report no significant increase in peripheral resistance was found in the studied patients, however, most of them were under angiotensin-converting enzyme inhibitors (ACEi) or angiotensin-receptor blocker (ARB) medications during the study.

\section{Antihypertensive Medication Removal during the Dialysis Procedure}

Pharmacokinetic characteristics are specific for each medication. Antihypertensive drug removal was reviewed by Chen et al. [2]. However, the specific effect of drug removal on the occurrence of IDH was not been specifically studied. There remains only one hypothesis (point 8 in table 1). ARBs and calcium channel blockers are not removed by dialysis. Several ACEi (captopril, enalapril, lisinopril, perindopril, ramipril) and $\beta$-blockers (atenolol, metoprolol, nadolol) are significantly re- moved by dialysis, whereas others are not (fosinopril, propranolol, pindolol, esmolol, bisoprolol, carvedilol, acebutalol). Among sympatholytics, clonidine is not cleared by dialysis, whereas $\alpha$-methyl-dopa is. Vasodilating agents are usually removed (minoxidil, diazoxide, nitroprusside), except for hydralazine and prazosin. The real use of this hypothesis is currently difficult to assess. It should be discussed if necessary when the other confirmed hypotheses have been treated.

\section{Treatment of IDH}

Management of IDH is summarized in figure 3. According to the Izmir reports $[3,12]$, it is clear that the firstline treatment of IDH is fluid removal. In these 2 studies, the amount of removed fluid was equivalent to $7.5-11 \%$ of the body weight in days or weeks. However, it must be done with caution to avoid hazardous BP drops that may occur in elderly or patients with severe comorbidity. Longer or more frequent dialysis may be necessary to avoid the UF side effects or hasten the amelioration of this complication. More complicated, however, is the therapeutic decision when a patient is at the end or even off dialysis with a high BP level, and sometimes with an important hypertension crisis. Theoretically, prolonging the dialysis 
session and the UF rate would be efficient, but this decision faces many difficulties such as patient refusal or the unit organization constraints. Empirically, these hypertensive crises are not persistent and usually the BP level quickly decreases spontaneously. But it is always difficult to discharge a patient with severe hypertension. Levin [1] indicates that calcium channel blockers are appropriate in this situation. However, the safety of these drugs in this particular situation has not been studied.

\section{Conclusions}

IDH is an unusual expression of extracellular fluid overload. It is found in $10 \%$ of HD patients. Its mechanism involves cardiac function improvement with UF and increased endothelin production. It is efficiently cor- rected by fluid removal. Confirmation of previous studies is necessary and unanswered questions remain. The relationship between fluid overload and endothelin production should be studied. We need to know if fluid removal improves cardiac function in heart failure dialysis patients presenting with intradialytic BP rise. It will be of great interest to study fluid excess in the IDH situation with bioimpedance techniques that might be helpful for the treatment as well as markers like brain natriuretic peptide during fluid removal in both hypertensive and heart failure patients with an intradialytic BP increase. We also need to study the spontaneous BP decrease after the end of the dialysis session as well as the need and safety for treatment of hypertension crisis in this setting. Improving our knowledge of this complication will contribute to decreasing the high burden of cardiovascular complications occurring in dialysis patients.

\section{References}

1 Levin N: Intradialytic hypertension I. Semin Dial 1993;6:370-371.

2 Chen J, Gul A, Sarnak MJ: Management of intradialytic hypertension: the ongoing challenge. Semin Dial 2006;19:141-145.

3 Cirit M, Akcicek F, Terzioglu E, et al: 'Paradoxical' rise in blood pressure during ultrafiltration in dialysis patients. Nephrol Dial Transplant 1995;10:1417-1420.

4 Chou KJ, Lee PT, Chen CL, et al: Physiological changes during hemodialysis in patients with intradialysis hypertension. Kidney Int 2006;69:1833-1838.

5 Amerling R, Cu G, Dubrow A, et al: Complications during hemodialysis; in Nissenson AR, Fine RN, Gentile DE (eds): Clinical Dialysis, ed 3. East Norwalk, Appleton and Lange, 1995, pp 242-243.

-6 Dorhout Mees EJ: Rise in blood pressure during hemodialysis-ultrafiltration: a 'paradoxical' phenomenon? Int J Artif Organs 1996; 19:569-570.

7 Inrig JK, Patel UD, Toto RD, Szczech LA: Association of blood pressure increases during hemodialysis with 2-year mortality in incident hemodialysis patients: a secondary analysis of the Dialysis Morbidity and Mortality Wave 2 Study. Am J Kidney Dis 2009; 54:881-890

8 Zager PG, Nikolic J, Brown RH, et al: 'U' curve association of blood pressure and mortality in hemodialysis patients. Medical Directors of Dialysis Clinic, Inc. Kidney Int 1998;54:561-569.
Inrig JK, Oddone EZ, Hasselblad V, et al: Association of intradialytic blood pressure changes with hospitalization and mortality rates in prevalent ESRD patients. Kidney Int 2007;71:454-461.

10 Raj DS, Vincent B, Simpson K, et al: Hemodynamic changes during hemodialysis: role of nitric oxide and endothelin. Kidney Int 2002;61:697-704.

11 Bazzato G, Coli U, Landini S, et al: Prevention of intra- and postdialytic hypertensive crises by captopril. Contrib Nephrol 1984;41: 292-298.

12 Gunal AI, Karaca I, Celiker H, Ilkay E, Duman S: Paradoxical rise in blood pressure during ultrafiltration is caused by increased cardiac output. J Nephrol 2002;15:42-47.

-13 Bode-Böger SM, Böger RH, Kuhn M, Radermacher J, Frölich JC: Recombinant human erythropoietin enhances vasoconstrictor tone via endothelin-1 and constrictor prostanoids. Kidney Int 1996;50:1255-1261.

14 K/DOQI Workgroup: K/DOQI clinical practice guidelines for cardiovascular disease in dialysis patients. Am J Kidney Dis 2005;45: S1-S153.

15 Locatelli F, Covic A, Chazot C, Leunissen K, Luno J, Yaqoob M: Hypertension and cardiovascular risk assessment in dialysis patients. Nephrol Dial Transplant 2004;19:10581068.

16 Chazot C: Can chronic volume overload be recognized and prevented in hemodialysis patients? Semin Dial 2009;22:482-486.

$\checkmark 17$ Locatelli F, Covic A, Chazot C, Leunissen K, Luno J, Yaqoob M: Optimal composition of the dialysate, with emphasis on its influence on blood pressure. Nephrol Dial Transplant 2004;19:785-796
18 Moret K, Hassell D, Kooman JP, et al: Ionic mass balance and blood volume preservation during a high, standard, and individualized dialysate sodium concentration. Nephrol Dial Transplant 2002;17:1463-1469.

19 Song JH, Lee SW, Suh CK, Kim MJ: Timeaveraged concentration of dialysate sodium relates with sodium load and interdialytic weight gain during sodium-profiling hemodialysis. Am J Kidney Dis 2002;40:291-301.

20 Oberleithner H, Riethmüller C, Schillers H, MacGregor GA, de Wardener HE, Hausberg M: Plasma sodium stiffens vascular endothelium and reduces nitric oxide release. Proc Natl Acad Sci USA 2007;104:1628116286.

21 Song JH, Park GH, Lee SY, Lee SW, Lee SW, Kim MJ: Effect of sodium balance and the combination of ultrafiltration profile during sodium profiling hemodialysis on the maintenance of the quality of dialysis and sodium and fluid balances. J Am Soc Nephrol 2005; 16:237-246.

22 van Kuijk WH, Wirtz JJ, Grave W, et al: Vascular reactivity during combined ultrafiltration-haemodialysis: influence of dialysate sodium. Nephol Dial Transplant 1996;11: 323-328.

23 Osanai T, Fujiwara N, Saitoh M, et al: Relationship between salt intake, nitric oxide and asymmetric dimethylarginine and its relevance to patients with end-stage renal disease. Blood Purif 2002;20:466-468.

-24 Osanai T, Saitoh M, Sasaki S, Tomita H, Matsunaga T, Okumura K: Effect of shear stress on asymmetric dimethylarginine release from vascular endothelial cells. Hypertension 2003;42:985-990. 


\section{Editorial Comment}

M. El Nahas, Sheffield

The editorial minireview by Chazot and Jean from the Tassin group in France addresses an important, overlooked and poorly understood complication of hemodialysis (HD), namely intradialytic hypertension (IDH). The authors uphold the concept that fluid overload and the associated hemodynamic changes underlie IDH. They also remind readers that sodium overload is central to IDH and the associated extracellular volume expansion. In spite of the growing evidence relating to the central role of a positive sodium balance in HD patients, nephrologists remain reluctant to impose stricter dietary sodium restrictions on their patients; instead they overemphasize the importance of fluid restriction. A low-salt diet should be a central part of the strategy to limit inter- and intradialytic hypertension. Emphasis on sodium restriction should also be shared with primary care physicians looking after dialysis patients [1]. A DASH-Sodium diet with dietary salt intake of $\sim 5 \mathrm{~g} /$ day should be promoted for HD patients [2].

\section{References}

Hirsch S: The internist's role in treating hypertension in hemodialysis patients. QJM 2009;102:501-507.

Lindley EJ: Reducing sodium intake in hemodialysis patients. Semin Dial 2009;22:260-263. 